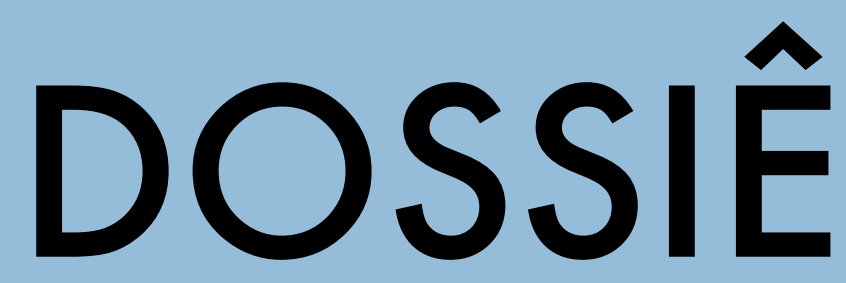

INDIGESTOS TRÓPICOS

ORGANIZAÇÃO: ANA CAROLINA PRUDENTE NASCIMENTO; ANA CLARA MATTOSO;

ANA SAYEG TRANCHESI; AUGUSTO MELO

BRANDÃO; THIGRESA ALMEIDA 


\section{APRESENTAÇÃO: PERGUNTE À TERRA}

Ana Carolina Prudente Nascimento; Ana Clara Mattoso;

Ana Sayeg Tranchesi; Augusto Melo Brandão; Thigresa Almeida

NASCIMENTO, Ana Carolina Prudente; MATTOSO, Ana Clara; TRANCHESI, Ana Sayeg; BRANDÃO, Augusto Melo; ALMEIDA, Thigresa. Pergunte à Terra. Revista Poiésis, Niterói, v. 23, n. 39 , p. 14-17, jan./jun. 2022. [DOI: https:// doi.org/10.22409/ poiesis.v23i39.52940]

Este documento é distribuído nos termos da licença Creative Commons Atribuição - Não Comercial 4.0 Internacional (CC-BY-NC) @ 2022 Ana Carolina Prudente Nascimento; Ana Clara Mattoso; Ana Sayeg Tranchesi; Augusto Melo Brandão e Thigresa Almeida
Indigestão: algo que fica, incomoda; embrulho no estômago, mas também retorno à boca. Necessidade de processar de outra forma. Adesão ao corpo diferenciada, impertinente, no entanto, eficaz em dar notícias sobre transgressão - indigestão não se contém nos limites, é perigosa, precisa transbordar.

Com o título Indigestos Trópicos, o Dossiê da edição 39 da Revista Poiésis visa propor uma reflexão crítica em torno do processo - geográfico, histórico e simbólico - de construção de um discurso da brasilidade. Diante do contexto político e social dos últimos anos, observamos um crescente interesse nas produções de algumes artisties, em questionar não apenas os símbolos da identidade nacional - bandeiras, estandartes e monumentos - como os espaços em que o discurso hegemônico sobre a identidade brasileira se produziu historicamente.

Na contramão do projeto positivista de ordem e progresso emergem práticas políticas e artísticas que denunciam certo estado de indigestão. Da negativa ao banquete conciliatório de uma imagem apaziguadora, esses experimentos parecem querer roer os contornos dos mapas, operando através desse gesto de borramento, novas estórias, imagens e ações. Quem sabe, para perguntar à terra, de suas fendas, de sua fome e de seu grito. 
Indigestos Trópicos apresenta-se assim como uma baliza, não determinante.

No precipício dessas inquietações, decidimos que além de coletiva, nossa indigestão seria também imprevisível. Assim, acionamos um convite-dispositivo a 6 artisties-pesquisadories com a seguinte proposta performativa:

\section{Convide outra pessoa, de sua livre escolha, para realizar com ela seu trabalho;}

2. A forma e o conteúdo são livres, mas a proposta, seja ela qual for, deve surgir do encontro de vocês, em coautoria;

3. Pedimos que, sempre que possível, levem em consideração o formato da revista, que não comporta vídeos, apenas imagens e textos.

Fosse através de um trabalho visual, um ensaio, um texto literário ou o que mais Ihes apetecesse, nossa proposição fundamentava-se no desejo de incrementar com dissonância uma receita intuitiva de curadoria aberta. Não sabíamos, naquele momento, que o acaso direcionado traria consigo contribuições tão pulsantes sobre transversalidade, fronteiras, imaginários sonhados-cruzados, e fricções entre a História contada e as estórias desviantes. Fabular o presente para sonhar com futuros mais possiveis e alegres para todes.
Os trópicos podem ser enfim remodelados em margens fluídas, vibrantes e furtivas, configurando resistências abrigadas em comunalidades e comunidades transitórias, espaços onde a borda invade o centro, e o centro se espalha sem retorno. Aqui, falamos de uma contra-exterioridade daquela produzida pelo que se convenceu chamar de centro. A borda produz, quebra e reorganiza os olhares. Desde a borda pensamos e articulamos este Dossiê. Desde o seu lugar da contra-exterioridade disparamos um gatilho: produzir uma dissonância no centro.

Depois de organizar, reorganizar estas ordens, de entender na prática, nas escritas, nas fotografias e relatos os Indigestos Trópicos, o que se configurava como uma provocação, um gatilho e até mesmo uma baliza, transfere-se para uma ação. Corpus Indigestos Trópicos, conceito Indigestos Trópicos, performance e ação Indigestos Trópicos.

Pensar neste dispositivo convidativo de produção para este trabalho de curadoria proporcionou que cada trabalho presente formasse sua própria teia com outres sujeitos, sejam pelas centenas de vozes que foram ouvidas pelo artista, professor e pesquisador Elilson e transmitidas em seu trabalho 123 ponteiros de Brasil; ou seja pela presença dos artistas fortalezenses Ednardo e Augusto Pontes; da artista cearense que nasceu no distrito de Quitaiús do município de Lavras da Mangabeira-CE, Maria 
Macedo; do artista da região do sertão do Ceará, Lívio Pereira ou escritor cearense,Thiago Florêncio, que foram presentificados no texto A arte brasileira não se resume ao eixo Rio de Janeiro - São Paulo: sotaques poéticos do Nordeste por uma urgente história da arte escrito às seis mãos de Eduardo Bruno, João Paulo Lima e Waldírio Castro.

Ou ainda, nas localidades e nas imagens dos trabaIhos Os Baobás do fim do mundo: trechos líricos de uma etnografia com religiões de matriz africana no sul do Rio Grande do Sul de Marília Kosby e Zé Darci e na Série Mapas de Talles Lopes, assim como os atravessamentos entre cinema e etnografia, embalados pelo tambor da macumba no texto de Camila Freitas e José Miguel Olivar.

Nesse sentido, Imagens trans: transe, fabulação e sobrevivências na fronteira, é encruzilhada na floresta, dando início as contribuições do dossiê com texto partilhado por Camila Freitas e José Miguel Olivar. Contextualizado na Tríplice Fronteira Amazônica entre Brasil, Peru e Equador, o "entre" é o elo fundamental para se orientar frente às experiências de corpos dissidentes em um território transfronteiriço-sempre em trânsito. Habitar a fronteira ecoa como aposta do encontro entre cineasta e antropólogo, nos alcançando com imagens-vagalumes de um tempo além do tempo.
Nossa bússola sem norte segue adiante nos levando até o enlace entre Eduardo Bruno, João Paulo Lima e Waldírio Castro, um texto-labirinto para repensar as produções deslocalizadas do sudeste a partir de outras localidades geográficas, históricas e simbólicas. A arte brasileira não se resume ao eixo Rio de Janeiro - São Paulo se estabelece perante a urgência de se produzir outras trajetórias para compreender o fazer da performance. Re-pensar a arte brasileira, os fazeres artísticos desde outros poros e porosidades que podem e vão expandir olhares das formas de contar a performance em seus dissensos brasilis.

Na sequência, trombamos com Julia Raiz e Maré em uma especulação futurista denominada: Com o que sonha Lula? Krenak sonha com lives. Sonha-se sonhos úmidos, sonhos de terra, de hormônios e formigas, o que é profundo e perpassa todas as existências - mesmo a das bisas em suas vidas aparentemente pacatas. Assim segue o baile, a prosa, o poema-experimento que provoca os os sentidos, imbrica imagens, panos de bandeira em um certo sarcasmo, elemento imprescindível a toda receita indigesta.

Numa reverberação não programada dos últimos trechos de Raiz e Maré, seguimos em outra parceria, dessa vez de Marília Kosby e José Darci Barros Gonçalves com Os Baobás do fim do mundo: 
trechos líricos de uma etnografia com religiões de matriz africana no sul do Rio Grande do Sul. Entretecidos em poemas e pinturas, o axé é materializado em caminhos plurais, apontando direções singulares e ainda assim coletivas.

Talles Lopes, com sua Série Mapas, torna quase tátil a experiência de fronteiras insubordinadas que desejávamos evocar no Dossiê. Não à toa, um de seus trabalhos, A Marcha (2018), foi escolhido como capa da Revista, onde nos inclinamos ao método cartográfico a partir de uma perspectiva confusa. As métricas seguidas pelo artista não se sujeitam a um olhar óbvio. No miolo de nosso Dossiê, já chegando ao fim das contribuições, chegamos ao ensaio visual de Talles, onde outros mapas nos convidam a distorcer as concepções tortas de um Brasil inventado. Em seus mapas, as linhas institucionalizadas da cartografia ocidental, já não são tão rígidas e inquestionáveis.

123 ponteiros incrementam nosso caldo com o tempero final, pois se antes pensávamos numa colaboração em dupla, Elilson traz à dança 123 vozes, coletando-as e colocando em movimento o passado de 123 anos de Juquery, complexo hospitalar e colônia psiquiátrica de São Paulo. A memória é viva, assim como as composições coletivas. Ao frisar o caráter da escuta em seu trabalho - no qual os relatos foram coletados a partir da oralidade - Elilson brinca com um cinema de voz, onde a contação de histórias pode criar novas imagens para estórias já esboroadas pelo tempo.

Assim fluímos, sentindo-nos também parte, participantes de uma rede costurada a muitas mãos, ouvidos, bocas e línguas. Olhares vastos para territórios de caminhadas infinitas. Nunca se esgotam. Lembrete para seguirmos atentes aos murmúrios do solo, ao que está acontecendo agora nas fendas insurgentes de um trópico amargo. Atentes às práticas artísticas engajadas num fazer partilhado, fazer este que ensaia metodologias experimentais abertas ao imprevisível. Nosso palpite é que doses homeopáticas - ou overdoses em alguns casos, quem sabe - de indisciplina, são capazes de, ao menos, transformar o indigesto em um motivo de reconhecimento de pares; reunião daqueles que seguirão conosco nas lutas por terras mais habitáveis e que celebram a possibilidade de traçar, juntes, outras formas de experimentar fronteiras.

NASCIMENTO, A. C. P.i MATtOSO, A. C.; TRANCHESI, A. S.; BRANDÃO, A. M.; AlmeidA, T. Apresentação: Pergunte à Terra. 